\title{
Zirkumzision
}

\section{Keine Angst mehr vor der Spritze}

- So mancher gestandene Mann will sich zwar beschneiden lassen. Es graust inm aber vor der betäubenden Spritze in das sensible Organ. Diese Sorge kann man Männern nehmen, denn es gibt eine Alternative. Das Anästhetikum kann auch mit einem Injektor per Hochdrucksprühstoß appliziert werden, wie ein amerikanischchinesisches Team nun an 60 Freiwilligen nachwies. Mit dem Injektor kann die zweiprozentige Lidocainlösung mit hohem Druck rund um das vordere Drittel des Penis

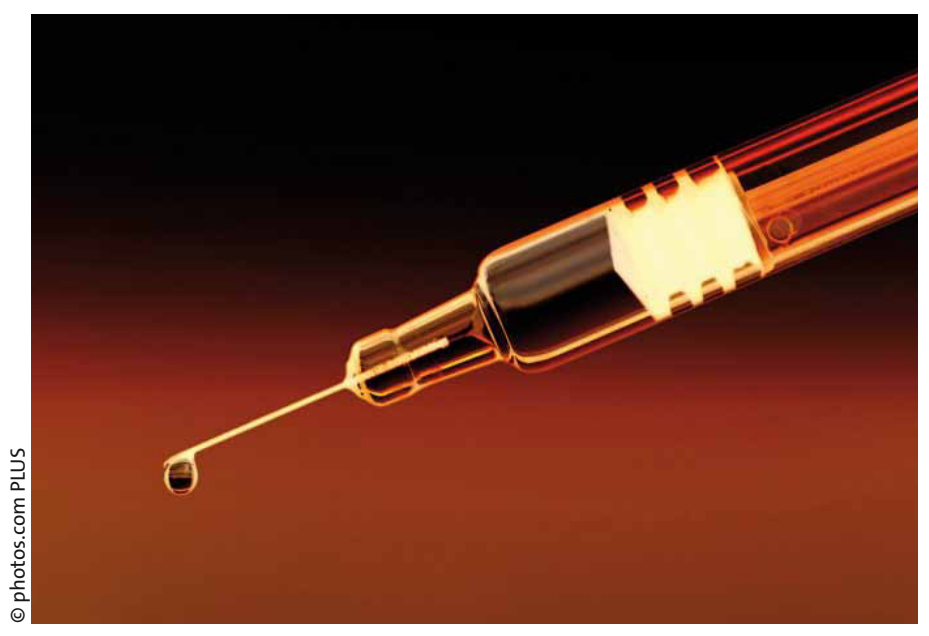

Um vor einer Beschneidung den Penis zu betäuben, bedarf es nicht unbedingt einer Spritze. aufgebracht werden. Schon 45 Sekunden später war das Anästhetikum durch die Haut aufgenommen worden und wirksam. Mehr als 85 Prozent der Studienteilnehmer benötigten keine weitere Betäubung. Die meisten Patienten beschrieben, die Prozedur fühle sich an wie wenn ein Gummiband reißt. Der VAS-Schmerzscore betrug direkt nach dem Eingriff 0,1, 24 Stunden später 6,8, während der Entfernung des Ringes 2,2 und nach der Entfernung 0,9. Bei vier Patienten kam es zu einer leichten urethralen Blutung, die sich durch Druck stillen ließ.

Die patientenfreundliche Alternative zur Betäubungsspritze ist demnach effektiv, schnell wirksam und sicher. Ob sich so mehr Männern für eine Beschneidung entscheiden, bleibt zumindest für Deutschland abzuwarten.

\section{Qualitätsmanagement \\ Viele Ärzte decken inkompetente Kollegen}

- Wenn es darum geht, Kollegen zu melden, die aus irgendwelchen Gründen nicht in der Lage sind, ihren Beruf korrekt auszuüben, sind viele Ärzte allzu zurückhaltend. Zu diesem Ergebnis kommt eine Umfrage unter rund 3.000 Ärzten verschiedener Fachrichtungen in den USA [JAMA 2010;304:1871-93]. Während die meisten Ärzte grundsätzlich überzeugt waren, dass es sinnvoll sei, berufsunfähige Kollegen zu melden, gab immerhin jeder dritte Befragte an, auf die konkrete Situation nicht vorbereitet zu sein. $17 \%$ berichteten, dass sie in den letzten drei Jahren schon einmal Kontakt zu einem Kollegen hatten, an dessen Kompetenz sie zweifelten, aber nur zwei Drittel hatten dies an die zuständigen Stellen gemeldet. Klinikärzte waren eher dazu bereit als Niedergelassene. 19\% nannten als Grund für ihre Zurückhaltung, dass sie hofften, andere Kollegen würden das Problem für sie lösen, $15 \%$ meinten, dass eine Meldung ohnehin keine Konsequenzen haben würde, und $12 \%$ befürchteten Nachteile für sich selbst.
DGU-Stipendium

\section{Neuer Anreiz für Forscher}

Rund 60.00o Prostatakarzinom-Neuerkrankungen im Jahr fordern größtmögliche Forschungsanstrengungen. Im Rahmen ihrer umfangreichen Forschungs-Initiative hat die Deutsche Gesellschaft für Urologie e.V. (DGU) nun ein Stipendium speziell zur Förderung der ProstatakrebsForschung ausgelobt, das Charles Huggins-Stipendium. Auf dem 62. DGU-Kongress Ende September in Düsseldorf wird das Kurzzeitstipendium erstmals vergeben. Das mit 10.000 EUR dotierte Charles Huggins-Stipendium soll es jungen, klinisch tätigen Urologinnen und Urologen unter 40 Jahren ermöglichen, für einen Zeitraum von maximal vier Monaten von ihren klinischen Pflichten freigestellt zu werden, um sich an einer ausländischen Forschungsinstitution auf dem Gebiet der Erforschung des Prostatakarzinoms weiterzubilden und neueste Methoden und Techniken zu erlernen. Das Stipendium soll alle zwei Jahre ausgeschrieben werden. Weitere wichtige Informationen können unter www.dgu-forschung. de/fileadmin/MDB/PDF/CH-Stipendium.pdf abgerufen werden. red 